\title{
Aperte start para começar: os jogos digitais na aprendizagem de língua inglesa
}

\author{
Fabielle Rocha Cruz ${ }^{\mathrm{i}}$ \\ Jacques de Lima Ferreira ${ }^{\text {ii }}$
}

\section{RESUMO}

Pensar em educação na atualidade sem refletir sobre o uso das tecnologias parece desconexo com a ideia da relevância e presença que estes têm em todos os âmbitos da sociedade. Assim, pensar em língua sem pensar no contexto dela entre os meios digitais parece não levar em conta como as tecnologias afetam os alunos. Este artigo baseia-se numa pesquisa de abordagem qualitativa do tipo bibliográfica e busca descrever como se relacionam a aprendizagem de língua, o letramento digital e os jogos digitais. Com a apresentação de cinco jogos de variados estilos, os autores propuseram seu uso para atender às necessidades da língua como meio, também, para outras disciplinas. Com base na interpretação da pesquisa, os autores consideram que os jogos digitais podem ser recursos significativos para a aprendizagem de língua em contexto.

Palavras-chave: Aprendizagem de língua; Aprendizagem mediada por jogos digitais; Língua Inglesa; Letramento digital; Jogos digitais.

\footnotetext{
i Graduada em Letras Português e Inglês pela PUC-PR, onde foi bolsista do Programa de Iniciação Científica da instituição e pesquisou o uso de videogames na aquisição de segunda língua. Em 2018, concluiu a pós-graduação em Educação Bilíngue, onde pesquisou sobre Letramento Digital e videogames em contextos interdisciplinares. No período de 2018 a 2019, foi bolsista do Departamento de Estado dos Estados Unidos e atuou como professora assistente de língua portuguesa na University of Notre Dame. Atualmente, é mestranda em educação da Universidade Federal do Paraná.

http://orcid.org/0000-0002-7239-2635 | ams.fabicruz@ gmail.com
}

ii Pós-Doutor pela Faculdade de Psicologia e de Ciências da Educação da Universidade do Porto Portugal, Pós-Doutor pelo Programa de Pós-Graduação em Educação da Universidade Federal do Paraná. Doutor em Educação pela Pontifícia Universidade Católica do Paraná - linha de pesquisa: Teoria e Prática Pedagógica na Formação de Professores. Mestre em Tecnologia em Saúde - Mestrado Interdisciplinar pela Pontifícia Universidade Católica do Paraná. Especialista em Metodologia do Ensino de Biologia e Química. Licenciado em Pedagogia e Biologia. Graduado em Medicina Veterinária. Tem experiência em Educação, com ênfase em Ensino e Aprendizagem na Educação a Distância, Ambiente Virtual de Aprendizagem, Meios Tecnológicos na ação Docente, Mediação Pedagógica e Coordenação Pedagógica. Desenvolve Estudos e Pesquisas sobre Formação de Professores e Metodologia da Pesquisa em Educação, principalmente nos seguintes temas: Formação de Professores em diferentes níveis e modalidades de Educação e Ensino, Desenvolvimento Profissional Docente, Prática Pedagógica, Tecnologias na Educação, Educação a Distância e Análise de Dados Qualitativos. Atualmente é Professor do Programa de Pós-Graduação em Educação: Teoria e Prática de Ensino (Profissional) e do Programa de Pós-Graduação em Educação (Acadêmico) da Universidade Federal do Paraná. Coordenador e professor do curso de Licenciatura em Pedagogia da UNICURITIBA

https://orcid.org/0000-0001-6364-8603 | drjacqueslima@ gmail.com 


\begin{abstract}
To think about education today without reflecting on the usage of technologies seems disconnected from the idea of the relevance and presence that they have in all areas of society. Thus, thinking about language without thinking about its context among digital media does not seem to take into account how technologies affect students. This article is based on a qualitative bibliographic research and seeks to describe how language learning, digital literacy and digital games are related. With the presentation of five games of various styles, the authors proposed their use to meet the needs of the language as a means, also, for other subjects. Based on the interpretation of the research, the authors consider that digital games can be significant resources for language learning in context.
\end{abstract}

Keywords: Language learning; Digital game-based learning; English; Digital literacy; Video games.

\title{
INTRODUÇÃO
}

A compreensão da educação e as formas que o ensino-aprendizagem agem sobre os alunos atuais, hiperconectados, muitas vezes com o acesso do mundo nas palmas de suas mãos, têm mudado o entendimento (GEE, 2017; PRESNKY, 2006; CASTELLS, 2007) que se tem das relações construídas em sala, bem como as práticas pedagógicas desenvolvidas pelos professores.

Num momento em que se reinventar é um processo mais do que necessário, a aula de língua não está distante dessa realidade. Ensinar a língua inglesa, por exemplo, é levar em consideração todo o poder que a língua tem, e que muitas relações atuais dependem do conhecimento desta. Por isso, encontrar novas ferramentas, recursos e meios para facilitar o entendimento do aluno é crucial para a promoção de um letramento crítico, onde o sujeito faz uso da língua para expressar-se e interagir com a sociedade a que pertence.

Entre as discussões que cercam o campo da educação e as perspectivas para o futuro dessa área, não há como trilhar caminhos que não perpassem pela influência que o meio digital e tecnológico tem na vida diária, não só de alunos, mas de professores igualmente. Portanto, integrar essas novas ferramentas às salas de aulas e quebrar com um ensino focado em livro didático, giz e livro é abrir portas para um ensino crítico, em que o aluno se sinta parte da produção do conhecimento. 
$\mathrm{Na}$ ideia dos letramentos, sobretudo no letramento digital, o aluno insere-se como agente, aquele que é responsável por construir seu próprio conhecimento. Destaca-se que para tal, o professor não perde espaço em sala, como será mostrado neste artigo, mas passa a não ser o único responsável pelo conteúdo e pelas discussões, permitindo que os alunos possam encontrar novas formas de interagir com os muitos meios que estão presentes na educação.

Tendo em vista a ideia do letramento digital e os meios multimodais, que são compostos por uma multiplicidade de meios textuais diferentes, este artigo insere os jogos digitais para a aprendizagem de língua inglesa. No Brasil e no mundo, várias pesquisas (GEE, 2017; PRESNKY, 2006; MAGNANI, 2015; ZACCHI, 2017; BRAGA, RICARTE, 2005) apontam que os games são valiosos para a aprendizagem, pois promovem ambientes contextualizados, oportunidade de interação, sistema facilitado de feedback, e muitos outros recursos que já são empregados pela educação.

Ademais, em muitos jogos, é indiscutível a presença de outras disciplinas curriculares, o que também promove a interdisciplinaridade e a língua como meio de ensino, ao invés do foco lexical e gramatical tão comum no ensino de língua estrangeira.

Por isso, considerando todos os aspectos que envolvem o ensino de língua inglesa e o letramento digital diante das novas reflexões impostas à educação, o uso de jogos digitais em sala de aula como uma ferramenta para o professor e o aluno deve ser entendido para ser utilizado.

Por meio de uma pesquisa de abordagem qualitativa do tipo bibliográfico, o presente estudo visa descrever como se relacionam a aprendizagem de língua, o letramento digital e os jogos digitais. Assim, os autores objetivam mostrar os limites e potencialidades existentes no uso dos games em sala, focando no processo de agência do aluno e o formato contextualizado que promovem.

Dividida em três seções principais, esta investigação irá retomar os conceitos da aprendizagem de língua inglesa de forma breve, seguido por uma discussão acerca do letramento digital e os jogos digitais, que já têm uma metodologia difundida por alguns pesquisadores. Por fim, os autores propõem alguns jogos digitais que podem ser utilizados em sala, articulando os conceitos e as ideias apresentados anteriormente como fundamentação. 
Na próxima seção, a aprendizagem de língua inglesa será discutida, relembrando o percurso que se fez até chegar aos dias atuais no ensino focado em contexto.

\section{APRENDIZAGEM DE LÍNGUA INGLESA}

A educação, de forma geral, passa por constante mudança conforme a sociedade (e tudo o que faz parte dela) avança, e o ensino de línguas não é diferente. Até o período da Idade Média, como apontado por Hummel (2014), latim e grego eram as línguas usadas para a comunicação do Império Romano, e tinham um status estabelecido na sociedade. Até 1800, com técnicas e métodos que datam de 207 A.D (HUMMEL, 2014), os alunos aprendiam vocabulário, de forma comparativa à língua mãe.

Com a ascensão da língua inglesa como uma língua dominante, que superou o francês e o alemão na sucessão do grego e do latim, questionamentos sobre a força e o poder que acompanham a língua se fizeram cada vez mais presentes. Isso também mudou as formas de ensinar.

Não obstante, esses questionamentos se intensificaram quando, cada vez mais, a língua inglesa passou a ser usada como segunda língua e língua estrangeira em muitos lugares, assumindo papel de língua de comércio e negociações. Nesse jogo de dominação e poder da língua, o ensino dela passou a ser cada vez mais questionado - a intenção já não é mais traduzir textos, mas se comunicar em contextos reais, saber expressar e portar-se em uma reunião de negócios, em uma viagem internacional ou, até mesmo, em uma entrevista de emprego.

Assim, não se pode desconsiderar que o método Grammar-Translation, que se baseava em tradução para a língua inglesa, teve seus dias de glória até meados do século XX (LARSEN-FREEMAN, 2008). Claro que, levando em conta o atual cenário do mundo, esse método não se adequa tão bem às necessidades. Entretanto, no seu auge, ele era cabível, pois seu foco era a leitura e a escrita em língua inglesa a partir de obras literárias, e o professor tinha um papel tradicional em relação à transmissão de conhecimento.

Com um método que contava com memorização de regras gramaticais e vocabulário, havia restrição na interação, pois focava-se no professor falando com o aluno, mas os alunos interagiam pouco ou nunca um com o outro. Como apontado por 
Larsen-Freeman (2008), o reconhecimento dos cognatos era o que importava, mais do que entender como a língua funciona em seu contexto. A prioridade era para memorização de partes do texto, sinônimos e antônimos, e assim por diante.

Com novas necessidades emergindo e o destaque que a língua inglesa foi ganhando no mundo, sobretudo por conta do mundo dos negócios, foi necessário mudar a abordagem. Então, uma proposta que cobrisse o máximo possível de conteúdo em pouco tempo foi apontada.

O Método Direto, conhecido por ter como uma única regra a não utilização de traduções, forçava o aluno e o professor a interagirem na língua, contanto apenas com recursos como os flashcards e outros materiais visuais. A herança do Método Direto deixado no ensino de língua é muito marcante, pois recursos visuais e mímica, por exemplo, ainda são muito utilizados - era uma abordagem que já trazia uma ideia multimodal, relacionando língua falada, escrita e imagens.

Para Larsen-Freeman (2008), o professor que seguia o Método Direto tinha a concepção de que o aluno deveria aprender a pensar na língua e usá-la principalmente para comunicação oral. Apesar de existir um apelo por falar de questões culturais dos países falantes da língua, a prioridade era para vocabulário e fala, ao invés de gramática e escrita.

Avançando um pouco mais nos principais métodos de ensino de língua, o próximo método que ganhou popularidade com a sua ênfase na oralidade e na gramática é o Audio-Lingual, que se propunha ao uso de drills - ensino de estruturas gramaticais fixas por seus padrões, o que permitia que o aluno os reproduzissem depois de muito praticar.

A ideia de ensinar os alunos a terem respostas imediatas para o estímulo, ou seja, uma frase fixa ou pronta, idealizava que o professor agisse como o "regente de uma orquestra, dirigindo e controlando o comportamento linguístico dos alunos" (LARSENFREEMAN, 2008, p. 45). Todo conteúdo novo era passado por meio de diálogos, inclusive gramática, e regras não eram explicadas, mas deixadas implícitas.

Muitos outros métodos nasceram depois desses, como o Total Physical Response (relação entre língua e sinestesia), método comunicativo e Task-based (foco em tarefas e atividades). Cada um deles contribuiu e ainda influencia, seja por meio de hábitos, atividades ou práticas, o ensino de língua inglesa, mas também servem como uma 
visualização de antigas formas de ensinar que já não condizem tão bem com o aluno do século XXI.

Atualmente, há uma grande discussão acerca do Content and Language Integrated Learning (CLIL), uma abordagem que leva em consideração uma segunda língua que é usada para ensinar tanto o conteúdo, quanto a língua adicional. Muito utilizado em escolas bilíngues ou internacionais, o CLIL se mostra atento aos questionamentos quanto a disputa existente entre a língua-mãe do aluno e a língua adicional.

Coyle, Hood e Marsh (2010) apontam que o CLIL mostrou que não apenas havia um alto grau de similaridade nas metodologias educacionais, mas também sucesso no quesito educacional. Ademais, o CLIL é uma abordagem que engloba diferentes metodologias, adequando-se para diferentes grupos de idade e situação de aprendizagem.

Observando o longo percurso traçado pelo ensino de língua, a preocupação da educação linguística sempre acompanhou as tendências e necessidades da sociedade no momento. Atualmente, como os alunos fazem parte de um mundo hiperconectado, com acesso facilitado à informação, a sociedade do conhecimento traz essa reflexão sobre o ensino de língua inglesa, por exemplo, num momento apropriado para o uso da tecnologia como ferramenta de apoio.

É indiscutível que todas as abordagens e métodos discutidos anteriormente são fundamentais para o entendimento do progresso no que tange ao aprendizado de língua. Porém, muito além disso, trazem à luz novas discussões de como os professores de inglês ainda se atêm a velhas práticas - como o uso de drills para fixar conteúdo da forma como é feito no Método Áudio-lingual, ou o uso de imagens, que tem suas origens no Método Direto.

Ademais, Hummel (2014) discute que há inúmeros problemas enfrentados na aula de língua, principalmente porque a preocupação é com um método cognitivo, que foque nos processos da segunda língua, ou com uma abordagem sociocultural, ainda enraizada em Vygotsky, focando na função social da língua.

Um dos debates que a autora traz é o excessivo foco na forma, de modo que o aluno recebe informações da língua formal, mas não é capaz de se comunicar num 
ambiente real, pois toda a estrutura e instrução que recebeu são oriundos de um ensino preocupado com a perfeição, e não o contexto.

Outro ponto que é passível de questionamento é no que diz respeito ao uso de feedback, e a forma com que o professor e aluno os articulam. Independentemente de a correção ser feita explicita ou implicitamente, Hummel (2014) aponta que muitos alunos não percebem os chamados recasts, que é quando o professor repete a frase dita pelo aluno, mas com a correção necessária. Então, é necessário repensar no uso das correções de uma forma que o aluno possa compreender e notar que foi corrigido, internalizando assim a forma correta.

Voltando ao questionamento acerca da tecnologia, nos anos finais do século XX, o Computer-assisted language learning (CALL) tornou-se uma tendência. Esse método, que se baseava em ensino de língua por meio de computador ou outros meios computadorizados, leva em consideração que o computador é um meio de inovação para o ensino e aprendizagem de uma segunda língua. Hummel (2014) aponta que o desenvolvimento e a acessibilidade do computador até os anos 2000 levou ao seu uso e implementação a fim de facilitar a aprendizagem das habilidades de língua.

Gee e Hayes (2011) ao discutirem língua e aprendizagem na era digital, mencionam que o mundo globalizado exige que as pessoas saibam mais do que apenas uma língua, e que esta é uma competência que será comum no século XXI. Além disso, os autores sugerem que os jovens estão engajados em atividades que proporcionam essa aprendizagem de forma muito mais ativa fora da escola, através de "mídias digitais e espaços de afinidade passionais" (2011, p. 104).

O espaço de afinidade passional, como proposto pelos autores, entende o aprendizado como parte da cultura popular. Ele ocorre quando as pessoas se organizam por seus interesses afins, seja no mundo real ou no ambiente virtual, para aprender ou compartilhar conhecimentos. Assim, pessoas que se organizam em um fórum internacional para discutir seu filme favorito - e, geralmente, a língua em comum é o inglês por sua forte presença hoje - estão participando desse espaço de afinidade.

Gee e Hayes (2011) comentam que a escola, de certa forma, é um espaço onde as pessoas se reúnem, da mesma forma como acontece nos espaços de afinidade. Mas de que forma a escola pode se tornar, cada vez mais, o espaço apropriado para tal discussão? E de que forma se relaciona com a aprendizagem de língua inglesa, se há a 
necessidade de uma produção em comum, seja a partilha de conhecimento, seja a articulação de novas óticas?

Assim, as tecnologias na aula de língua estrangeira são e devem ser um ponto a ser discutido, sobretudo pensando a partir do letramento digital, que será apresentado na próxima seção.

\section{LETRAMENTO DIGITAL, DGBL E JOGOS DIGITAIS}

Com tantas mudanças acontecendo no mundo, sobretudo com as novas tecnologias que emergiram - afinal, a escrita é uma tecnologia igualmente -, a educação não pôde deixar de acompanhá-las. Al-Qallaf e Al-Mutairi (2016, p. 523) mencionam que tal avanço tecnológico, em especial nas tecnologias de informação e comunicação, possibilitou novas práticas pedagógicas que "redefiniram os meios convencionais de ensino e aprendizagem".

O que os autores discutem é, como sempre, uma reflexão que engloba todas as disciplinas que fazem parte do currículo, e a língua estrangeira também faz parte desse pensamento. As tecnologias, que podem ser tanto aliadas quanto ameaças à educação, devem ser utilizadas com o cuidado e com o rigor do conteúdo que trazem, contribuindo para a formação do aluno como um cidadão capaz de reflexões, não apenas uma vaga forma conteudista de aula com slides e imagens projetadas em um computador.

Desse pensamento, nasceu o letramento digital. Parte dos multiletramentos, o letramento digital traz os letramentos, ou seja, a habilidade de fazer a leitura de textos, mais a ideia do digital. Assim, o letramento digital compreende as habilidades necessárias para ler os muitos textos que fazem parte do mundo altamente tecnológico, desde uma coluna em um jornal e uma mensagem de texto em um celular, até uma publicação em rede social ou um vídeo que foi enviado eletronicamente.

O letramento digital entende o acesso à informação como algo necessário e complexo. É essa informação que está em um meio facilitado, cercada por outros gêneros e formas textuais - esse conceito se chama multimodalidade, e entende-se que não há apenas os elementos linguísticos, como palavras e frases, mas outros componentes, como imagens, sons, ícones, vídeos, cores e assim por diante. Cada 
pedaço forma o todo, e o letramento digital visa interpretar e ler cada um deles para compreender o objeto completo.

Pensando nessa questão do letramento digital, Mohammadyari e Singh apontam que ter competências desenvolvidas pelo letramento digital é ter o conhecimento de várias tecnologias e reconhecer o impacto delas sobre a sociedade e os sujeitos que a formam, pois "permite que os indivíduos se comuniquem com os outros, trabalhem com mais eficiência e aumentem a produtividade" (2015, p. 15).

Da mesma forma, a ideia de se utilizar as tecnologias para ensinar língua não deveria estar distante dessa realidade, pois são elas que podem permitir o contato com o uso contextualizado do inglês, por exemplo. Para Cruz o letramento digital, então, leva em consideração que "a leitura e a escrita ganham espaço na dimensão virtual [...] demandando, assim, outras habilidades para ler e escrever, ao mesmo tempo que o mundo exige adaptações sociais, discursivas e cognitivas" (2020, p. 54).

Em consonância com que a autora propõe, Ryberg e Georgsen (2010) também incitam que o letramento digital deve ser parte da realidade da escola, pois é só a partir da prática que se pode desenvolver um maior entendimento da ideia por trás dele. Se a escola oportunizar esse espaço para alunos e professores dialogarem digitalmente, ela se torna um espaço acolhedor e motivador, que proporciona o encontro com as multimodalidades.

Além disso, há muitos meios digitais que podem ser utilizados para a aprendizagem, como $b \log s$, redes sociais, fóruns online e, como proposto por este artigo, os jogos digitais. De certa forma, eles estão presentes em grande parte das moradias atualmente, e ao alcance das mãos, mas devem ser cuidadosamente inseridos na realidade educacional para não serem simplesmente disruptivos e contraproducentes.

Portanto, tendo em mente o letramento digital e a melhor forma de aplicar os video games em aula, o Digital Game-Based Learning (DGBL) traz respostas para inúmeros questionamentos. Conhecido como Aprendizagem mediada por jogos digitais, o DGBL proposto por Prensky (2007) é pautado em três aspectos principais, sendo eles atender às necessidades e estilos de aprendizagem das gerações atuais e futuras, ser motivadora por ser divertida e, por fim, ser versátil, adaptável e efetiva, em qualquer que seja o conteúdo. 
Para o autor, não se pode educar uma geração atualizada com velhas tradições. Ao contrário, é necessário centrar a educação naquilo que é efetivo, que o aluno se sinta atraído e interessado. Nesse mesmo rumo, Gee e Hayes (2011) sugerem que toda a criança que está na escola tem conhecimento de língua, seja ela escrita e/ou falada, mas há muito outros textos para serem conhecidos, além do que o livro didático, por exemplo, é capaz de trazer.

Prensky (2007) também reitera que, atualmente, o mundo está convivendo com a geração game, uma geração que cresce com traços cognitivos muito diferentes das gerações anteriores. O autor cita que há aumento na velocidade de pensamento, atividades ativas em detrimento de atividades passivas, momentos conectados e o processamento paralelo das ações.

Pensando nessas características, o DGBL entende que o elemento da imersão é importante para a aprendizagem, pois o aluno/jogador está envolvido com o contexto do jogo, e esse fator é um diferencial para aqueles alunos que têm dificuldade em se sentar e ouvir apenas, ao invés de produzir ativamente seus conhecimentos.

Além disso, a questão do processo interativo de aprendizagem também traz vantagens únicas para o DGBL, como o envolvimento e a curiosidade que é desperta no aluno pelo caráter de motivação e instigação. É de se pensar que, assim como qualquer metodologia, o DGBL deve estar em consonância com o conteúdo e o aluno. Caso contrário, não será efetivo. Por isso, o processo interativo favorece a imersão do aluno em um momento divertido, muitas vezes ignorado pelo professor com a ideia de que a diversão não é parte (ou não deveria ser) do processo educacional.

Outro ponto que o DGBL leva em consideração é que a tecnologia digital é parte integral da vida das crianças, pois elas já nascem nesse contexto. Entretanto, muito professores são o que Prensky (2006) chama de imigrantes digitais, e isso é o que causa a sensação de desconexão entre o professor e o aluno. Um imigrante digital nada mais é do que aquela pessoa que nasceu antes do advento da tecnologia, tendo que aprender a utilizá-la conforme ela foi sendo divulgada - provavelmente, é alguém que conheceu o disquete, o antecessor do pendrive em muitas gerações.

Os nativos digitais recebem e compreendem a informação em uma velocidade muito acima do que os pais e professores, que são imigrantes digitais, são capazes de propor. Ademais, os alunos nativos estabelecem uma necessidade de gratificação e 
feedback instantâneos durante seu processo de aprendizagem, e é por isso que ele é um processo ativo e imersivo.

Com todas essas características dos nativos digitais, os jogos digitais parecem se adequar muito bem à realidade, pois fatores como feedback, gratificações e velocidade no acesso à informação são parte de como a maioria dos video games funcionam. Presky $(2006,2007)$ inclusive aponta que os alunos de hoje não são os mesmos para os quais o sistema educacional foi pensado, além de seus cérebros já estarem num desenvolvimento diferente do que anos atrás. Presky reitera que:

\begin{abstract}
Nossas crianças sabem, instintivamente, que, em uma época em que o conhecimento e o poder da tecnologia aumentarão milhões ou talvez bilhões de vezes em suas vidas, as habilidades que precisarão no futuro não são as habilidades do passado, por exemplo, as que são ensinadas na escola. [...] Nós teremos que aceitar que nossas crianças realmente mudaram, e que elas precisam que façamos coisas diferentes de diferentes maneiras. Nós teremos que aceitar algumas coisas que são novas, estranhas e assustadoras para nós, como jogos de computador e video games. (PRESKY, 2006, p. 31)
\end{abstract}

Nessa mesma linha, é possível pensar que as línguas também passam por esse movimento tecnológico e é inevitável que elas precisem dessa atenção contextualizada, pois o que mais importa é seu uso real, e não estruturas fixas - sendo que a linguística considera que a língua é uma unidade viva, sempre se adaptando às necessidades de uso dos seus falantes.

Assim, não tem como se descartar que a língua inglesa, no contexto deste artigo, pode e deve ser ensinada por meio de jogos digitais ou, até mesmo, ser utilizada como meio para ensinar outra disciplina dentro dos contextos propostos pelos video games. Shaffer (2006) discute que livros, games e filmes da cultura das crianças de hoje em dia exigem pensamento estratégico, habilidades para solução de problemas e, não menos importante, conhecimento de língua. A língua apresentada nesses ambientes tende a ser mais sofisticada ou mais específica do que o que será apresentado no livro didático, que se restringe ao necessário, mas não ao contextualizado.

Refletindo sobre essa situação com o livro didático, Gee (2017) menciona que a linguagem presente nos livros didáticos geralmente se associa com seu público, que são professores e pessoas com motivações políticas e sociais. $\mathrm{Na}$ esperança de que o conteúdo seja adequado a visão que propõe, há muito que é deixado de fora por razões de motivação pessoal desses grupos. O autor ainda entende que é importante que o aluno aprenda a pensar sobre a língua e que a comunicação gera entendimento sobre ela. 
Assim, os jogos digitais também oportunizam a ideia de que o aluno possa se relacionar com a língua e usá-la efetivamente. Certamente que muitos contextos podem ser difíceis de serem explorados, mas os games apresentam soluções para isso de acordo com seu conteúdo, e a relação interdisciplinar da língua como meio não deve ser descartada.

Por fim, na próxima seção, os autores propõem alguns jogos digitais que podem ser utilizados para desenvolverem habilidades dos alunos, em contextos, acessos e disponibilidades diferentes.

\section{OS JOGOS DIGITAIS PARA APRENDIZAGEM DE LÍNGUA INGLESA}

Como trazido nas seções anteriores, a utilização dos jogos digitais para a educação tem grandes contribuições, em especial para a área de língua inglesa, que pode ser o foco ou o meio de se ensinar com os games. Nessa seção, então, os autores trazem alguns exemplos de jogos digitais que podem servir como ferramenta para promoção de uma educação mais motivadora, divertida e contextualizada.

O primeiro jogo pensado dentro desse contexto é Cities: Skylines, um jogo lançado em 2015 pela empresa Paradox. Esse game, que foi lançado para computador e console (XBOX, PlayStation 4 e Nintendo Switch), foca em uma simulação de cidade. A ideia é construir estradas, estações de tratamento de esgoto e tudo que o gerenciamento de uma cidade requer, enquanto o jogador tenta manter a população feliz.

Apesar desse jogo ser single player, ou seja, para um único jogador, ele promove discussões e estratégias que requerem a reflexão, então o professor pode dividir os alunos em grupos ou duplas, permitindo que pensem juntos e, depois, produzam uma apresentação, um debate ou um texto para explicar como foi o desenvolvimento de sua cidade.

A língua aqui é vista como uma necessidade, uma vez que a população se comunica com o jogador/aluno por mensagens que aparecem na tela. O jogo não tem recurso de voz, então o contato está com a língua escrita por meio dessas mensagens e dos comandos do jogo, como mostrado na Figura 01 a seguir. Cabe aqui o professor 
como mediador do conhecimento, possibilitando que os alunos conversem e discutam o que está no jogo.

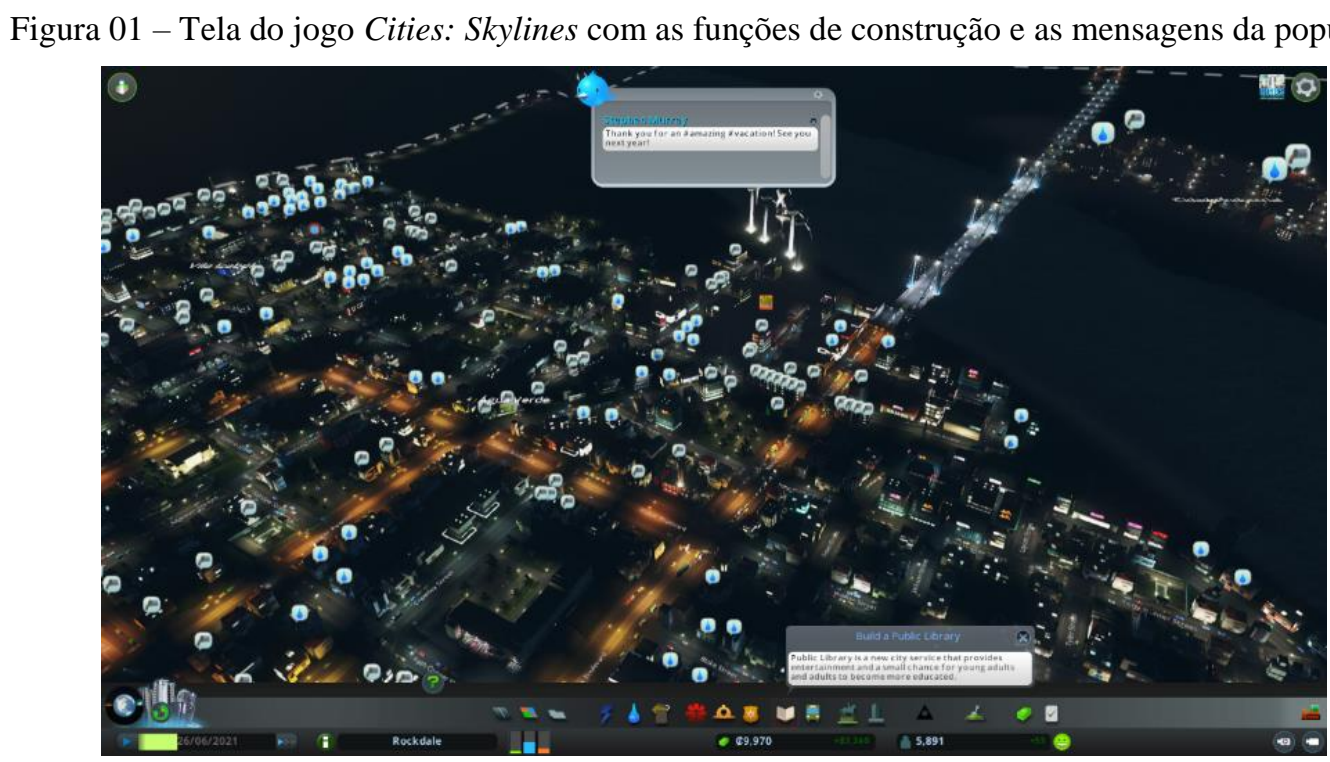

Fonte: Paradox.

No aspecto interdisciplinar e no uso da língua como meio, Cities: Skylines oportuniza discussões de geografia e ciências biológicas, uma vez que lida com questões de poluição, distribuição de setores de residência, comércio e industrial, energia renovável e não renovável. Também pode trazer uma discussão valiosa para a matemática, ao envolver quantificação, preços e empréstimos financeiros para o melhor gerenciamento da cidade.

Uma das potencialidades desse game é que ele não é limitado, não tem nível e não depende de longas horas de jogo. Por exemplo, o jogador já começa a partida com o objetivo de começar sua cidade de algum lugar.

De acordo com o Entertainment Software Rating Board (ESRB), que avalia a faixa etária apropriada para cada jogo digital, Cities: Skyline é considerado um jogo para todas as idades, o que permite ser utilizado com alunos a partir do ensino fundamental, desde que o professor atue como mediador e proporcione a interação das crianças com o jogo.

Um segundo jogo pensado para a língua inglesa é Overcooked! 2, lançado em 2018 para computador e console pelo Team17. Em Overcooked, os jogadores devem 
administrar cooperativamente uma cozinha, lidando com tempo, clientes esfomeados e habilidades divertidas de solução de problemas.

Esse jogo tem uma história por trás, que pode ser explorada pelo professor, e conta com vários níveis curtos, que não dependem de uma aula inteira para serem concluídos. Por ser cooperativo, ele permite que até quatro jogadores dividam a cozinha em situações inusitadas, cozinhando para pessoas de diferentes nacionalidades e, até mesmo, monstros.

Aqui, no que diz respeito à produção de língua, os alunos dependem um do outro para avançar nos níveis e concluir as missões com sucesso. Portanto, a língua inglesa pode ser o principal meio de comunicação entre eles - levando em conta que precisam se ajudar, o uso das formas imperativas (give me, pass me, come here, help him) pode ser uma excelente razão para utilização deste jogo, contanto que o professor já tenha abordado esse ponto gramatical anteriormente.

Conforme mostrado na figura 02 abaixo, Overcooked! 2 traz diversos ingredientes e receitas. Por meio delas, conteúdos de história, geografia e ciências biológicas podem ser retomados, entendendo a origem de alguns pratos, a questão dos ingredientes escolhidos e o caráter saudável deles.

Figura 2 - Tela do jogo Overcooked! 2 com as receitas pendentes.

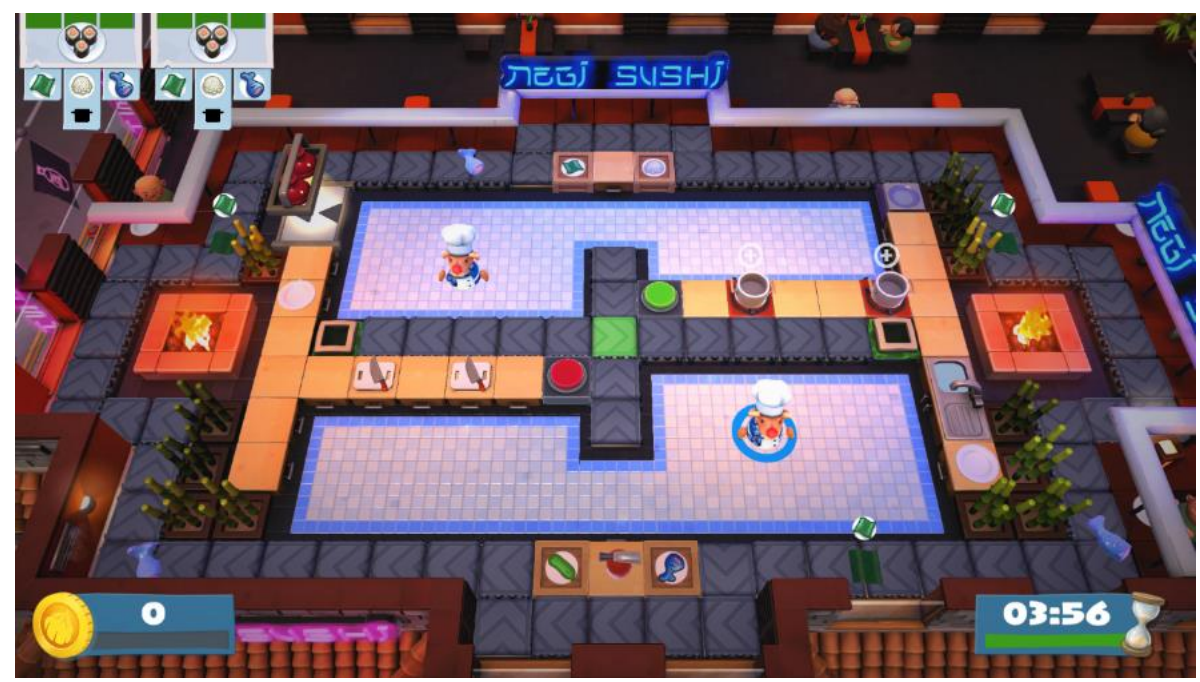

Fonte: Team17.

Uma sugestão que tem uma boa relação com a literatura é o jogo Orwell, baseado na obra 1984 de George Orwell. Tendo sido publicado em 2016 no formato 
para computador, esse game distópico e de simulação de literatura traz a história do livro através de uma realidade em que o jogador/aluno é parte do controle da população.

Apesar de estar alinhado com o uso das obras do autor em muitas escolas, o ESRB o considera um jogo para um público maduro, o que o torna uma boa ferramenta para alunos do ensino médio, e traz a ideia do livro de uma forma aplicada. Mesmo sendo single player, o jogo permite que cada pessoa tenha sua própria experiência com a história, e permitiria, por exemplo, que o professor utilizasse discussões posteriores a experiência do jogo para retomar ideias do livro.

Uma das vantagens desse jogo, publicado pelo Fellow Traveller, é ter sido produzido em episódios. Apesar de serem consideravelmente longos, o professor poderia adequá-los à sua aula e permitir que os alunos tivessem contato ao menos com a primeira parte, entendendo os contextos e relembrando elementos clássicos da história escrita por Orwell, que dá título ao jogo.

Na Figura 03, é possível observar a tela de comando do jogador, que simula a investigação de sujeitos que não estão cumprindo as ordens da cidade. Da mesma forma que acontece na narrativa do livro, as pessoas são submetidas a constantes análises, e isso pode ser relacionado com conteúdo de história mundial, sobretudo regimes autoritários ou ditatoriais, bem como a relação do jogo com a literatura e, até mesmo, os filmes que existem baseados no romance 1984 .

Figura 3 - Tela do jogo Orwell, mostrando as funções disponíveis para o jogador investigar as situações propostas.

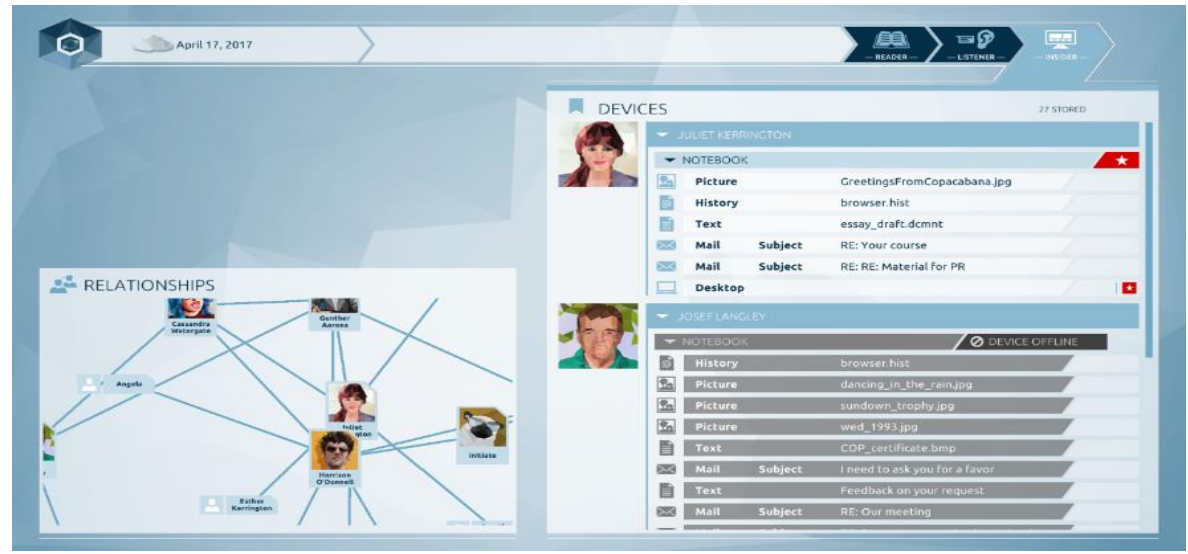

Fonte: Fellow Traveller.

Quanto ao fator da língua inglesa desse jogo, é indicado que ele possui um vocabulário pesado, com gírias e expressões inapropriadas, o que pode ser um trabalho 
difícil. Entretanto, se o professor consegue estabelecer a conexão do jogo com a obra literária, aspectos como a escolha de palavras e a forma com que a língua se molda para a necessidade do falante podem ser explorados também.

Outro ponto interessante que pode ser abordado por meio da língua são questões de caráter filosófico e sociológico, uma vez que o game aborda muitas indagações morais, tanto do jogador, quanto dos personagens presentes na narrativa. A língua pode ser usada como meio de interpretar e discutir essas reflexões criticamente e em contexto, pois requer muita astúcia por parte do jogador para entender quem são os culpados reais no contexto do jogo.

A proposta de se utilizar o jogo Don't Starve Together também é interessante. Este game, publicado pela 505 Games em 2013, está disponível para computador, celulares e consoles, sendo de acesso fácil.

Mesmo com uma ideia que parece simples - sobreviver no mundo -, o jogo permite que os jogadores trabalhem juntos para conseguirem vencer seus medos, a fome e os desafios por mais um dia. Como é cooperativo, permite que os jogadores conversem entre si e encontrem a melhor maneira de cultivar frutinhas, evitar que monstros os ataquem e usar tudo o que a natureza oferece para aguentar até o inverno.

Indicado pelo ESRB como conteúdo para adolescentes, poderia ser aproveitado pelos últimos anos do fundamental II e alunos do ensino médio para praticar alguns pontos gramaticais, como verbos modais (can, should, must) e frases no presente perfeito (presente perfect para falar de ações não datadas do passado e/ou que ainda afetam o presente). Assim, no contexto, os alunos poderiam desenvolver estratégias de sobrevivência com a utilização do conteúdo que aprenderam, além de ter contato com várias palavras novas: o jogo conta com um bisão que produz manure, ou seja, esterco para fertilizar as plantas.

Há muitas disciplinas que podem ser articuladas com esse jogo, como matemática, geografia, química e biologia. Usando a língua como meio, os alunos precisam criar objetos e itens que os auxiliem na sobrevivência, como mostrado na Figura 04. Para isso precisam entender como ingredientes e elementos funcionam, bem como tomar cuidado com o tempo de produção das plantas, observar o uso de esterco para fertilizar as plantas, vigiar o acesso às flores (que não renascem) e, até mesmo, evitar a queimada, que poderia simplesmente destruir tudo o que criaram. 
Figura 4 - Tela do jogo Don't Starve Together com os recursos disponíveis

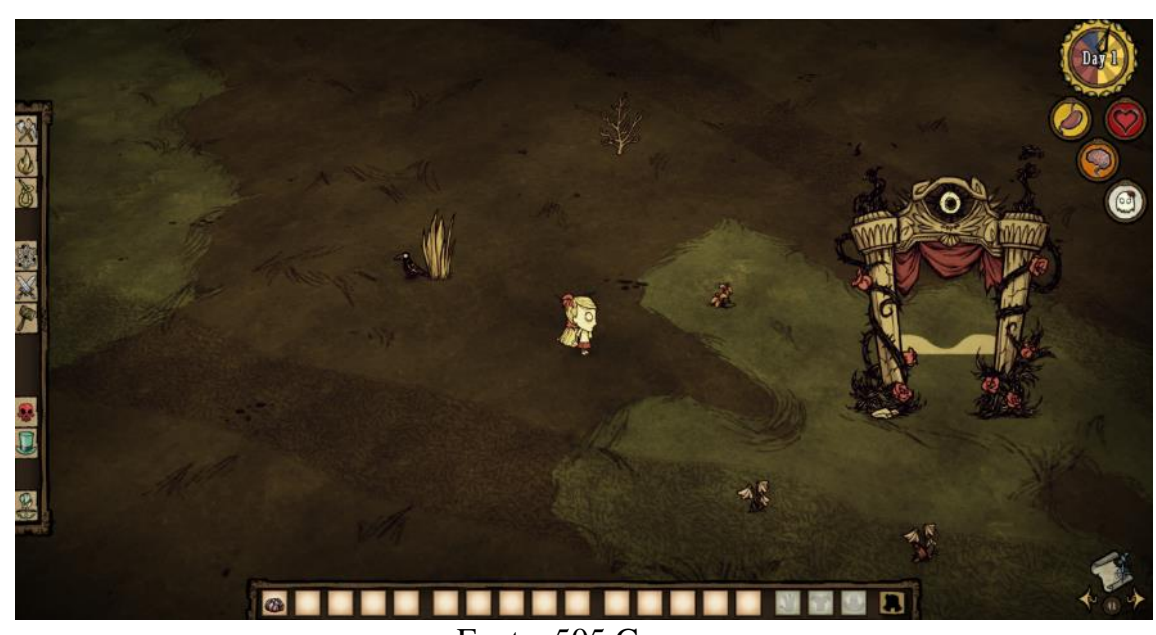

Fonte: 505 Games

Como dito anteriormente, Don't Starve Together tem uma premissa muito simples, mas pode ser utilizado para a prática de conteúdos gramaticais que são constantemente descontextualizados e considerados sem graça. Além disso, por não depender de nível, o professor pode propor que os alunos encontrem maneiras de sobreviver às primeiras noites no jogo, refletindo criticamente em como cada ação tomada tem uma consequência que impacta diretamente no grupo todo.

Talvez um dos jogos mais famosos e mais populares do mundo, é impossível pensar no uso de video games na educação e nas aulas de língua sem pensar em como The Sims 4 tem muitas mecânicas que tornam a aprendizagem positiva, além de englobar praticamente todas as disciplinas curriculares com sua jogabilidade simples e imersiva.

Publicado pela Electronic Arts em 2014 (e com rumores da sua $5^{\text {a }}$ geração programada para os próximos anos), esse jogo single player simula a vida real, desde a vida em família e a abordagem de questões sociais, até a estabilidade financeira, bichos de estimação, estações do ano e muito mais. Mesmo sendo para um só jogador, há muito o que se explorar em conjunto em The Sims.

Uma das mecânicas mais interessantes desse simulador está no desenvolvimento pessoal, profissional e emocional do personagem, o que permite uma miríade de abordagens e disciplinas a serem trabalhadas, tudo por meio da língua inglesa. Por exemplo, refletindo em relação à química e à biologia, o jogo permite que o personagem se torne um cientista que inventa o elixir da imortalidade, ou um médico que trabalha 
com micróbios. Cada uma dessas possibilidades traz ideias que os alunos conhecem em sala.

Ou, em de pensar pelas ciências da natureza, trazendo a área de exatas, é com os conhecimentos de matemática e física que os jogadores constroem e mobíliam suas casas, bem como administram suas economias. Um personagem autônomo ganharia mais ou menos do que um empregado, como comprar aquela cama melhor sem dinheiro, e outras indagações propostas pelo professor podem contribuir para a interpretação dos alunos de tudo o que fazem, no jogo e na vida real.

Como sua proposta é ser um simulador de vida, acompanhando o progresso da infância à terceira idade (se assim o jogador desejar), o vocabulário do jogo é muito rico. Através do uso de verbos e expressões para descrever cada pequena ação, como mostrado na Figura 05, a língua inglesa é parte do jogo e, ainda que não seja o foco, ela deve ser estimulada nesse ambiente imersivo, juntamente aos questionamentos mencionados anteriormente.

Figura 5 - Tela do jogo The Sims 4 com foco nas ações através do uso de vocabulário

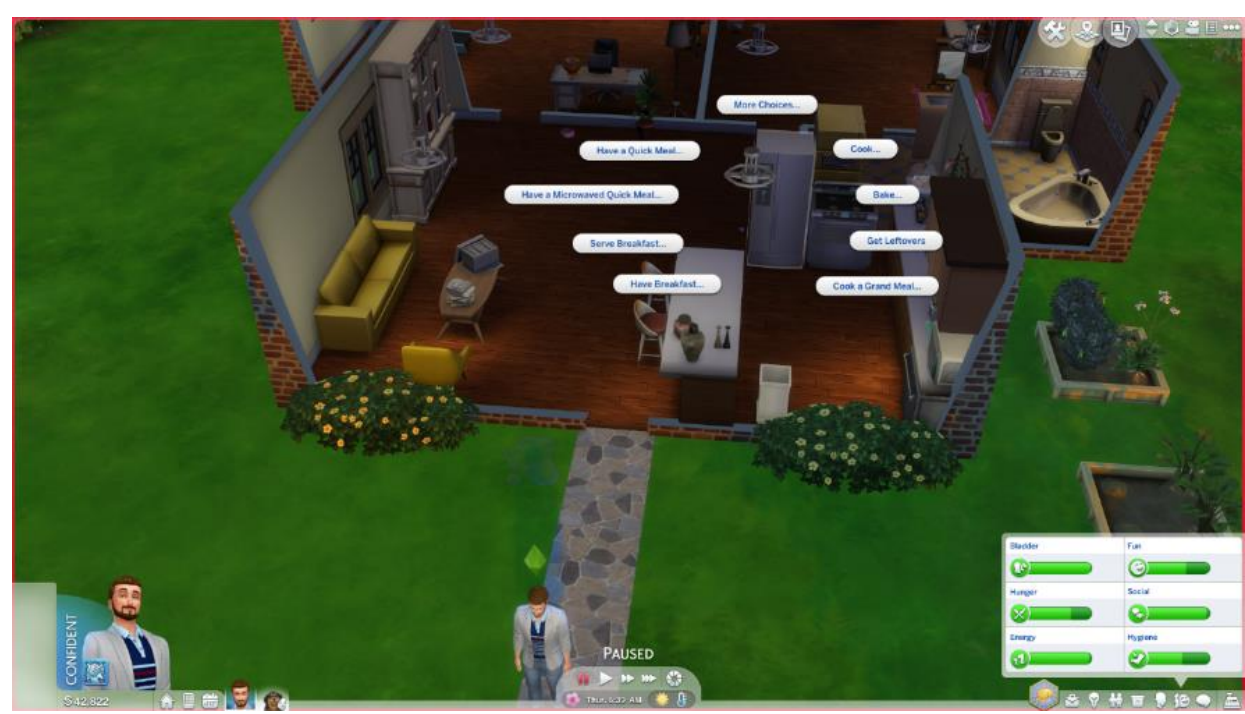

Fonte: Electronic Arts

Além disso, uma das maiores contribuições de The Sims 4, ao longo de seus vinte anos de existência, tem relação com uma temática que é muito discutida em sala. O jogo sempre deixou que o jogador criasse seu personagem, mas, atualmente, ele permite espaço maior para representatividade, incluindo personagens com tons de pele variados, gordos ou magros, que usem aparelhos dentários, tenham cicatrizes e, mais 
importante de tudo, que sejam do gênero que quiserem. Esse ponto da representatividade, muitas vezes excluído pelo livro didático, pode significar que muitos alunos irão se identificar (talvez pela primeira vez) com um personagem, afinal, o jogo possibilita a escolha do sexo biológico e do gênero com o qual o personagem criado se identifica.

É importante pensar essas questões no contexto atual da educação, pois, cada vez mais, alunos que não se sentem seguros na sociedade são uma realidade na sala de aula. Talvez, por meio de conhecimentos das aulas de biologia, filosofia, sociologia, geografia e história, muitas dessas mudanças sociais possam ser debatidas de uma maneira que não entre em conflito com nenhuma crença.

Ademais, com a oportunidade de criar o personagem que se quer, questões raciais e discussões a respeito dos direitos femininos podem ser trazidas como uma contribuição também, tudo por meio da língua inglesa. Já que o jogo permite criar uma mulher negra, mãe solteira de dois filhos - que é uma realidade no Brasil -, com o incentivo do professor, os alunos poderiam passar por um exercício de empatia e entender como é a vida dessas pessoas, marginalizadas social e economicamente.

The Sims 4 tem uma riqueza de recursos que pode demorar para ser explorada, mas, por não depender de tempo ou nível, e sim do crescimento físico dos personagens que vão envelhecendo, o professor pode propor desafios aos alunos, sugerindo que criem personagens de grupos minoritários e tentem se desenvolver com estudo, trabalho, família, e muitos outros pontos que são reais, para aplicá-los em seus dia-a-dia e entender como as questões funcionam fora do jogo.

Os jogos que foram citados aqui não são desenvolvidos, de modo algum, com fins educacionais, e isso os torna mais autênticos e contextualizados, sobretudo ao trazer temas e reflexões que contribuem para a formação do aluno como um cidadão que interage e molda a sua realidade.

Pensando em como trabalham com a língua, nenhum deles têm a finalidade de ensinar o conteúdo de língua. Ao contrário, suas propostas são entreter, instigar e permitir que o aluno/jogador interaja com os conteúdos curriculares sem sequer notar que é um momento de aprendizagem - quando Presnky (2007) fala do processo interativo de aprendizagem e Gee (2017) aponta que os jogos promovem a 
aprendizagem ativa, é disso que se trata. É assim que se permite ao aluno ser agente de seu conhecimento, aquele que aprende na imersão, no contexto.

Claro que jogos como Orwell e The Sims 4 tendem a criar controvérsias, em especial pelo seu conteúdo permissivo e que trata de muitas temáticas mais sérias. Entretanto, o professor pode usar essas mesmas dificuldades em debates construtivos e reflexivos dentro da sala. Afinal, se os alunos entendem que são controversos, o que há na sociedade que favorece ou se opõe às ideias?

A importância do professor para esses jogos não é de jogador ou de participante ativo, mas de permitir que os alunos estejam imersos na oportunidade, mediando e acompanhando seus progressos. Se o professor for um imigrante digital, talvez tenha um pouco mais de trabalho para desenvolver sua proposta, mas basta que se jogue um pouco para entender a mecânica que articula o jogo.

Quanto ao uso de língua, Cruz (2020, p. 63) sugere que "ter a noção de que o conhecimento em nível básico da LI pode, por um lado, ser um momento estimulante que promoverá a vontade de aprender cada vez mais, avançando e progredindo no jogo", ou o jogador/aluno pode sentir-se desmotivado e procurar um jogo que tenha tradução. Assim, o professor também precisa pensar em materiais de apoio para os alunos, como o próprio livro didático, dicionário ou mesmo imagens.

\section{CONSIDERAÇÕES FINAIS}

Apesar do uso das tecnologias na educação ser um assunto corriqueiro, há muitos debates e pesquisas a serem desenvolvidos, e a questão das línguas não fica atrás. Mesmo com o progresso considerável, ainda há a presença marcante de antigos métodos e abordagens, que já não condizem mais com a realidades dos alunos.

Com a leva dos professores imigrantes digitais, os nativos digitais chegam em sala e se deparam com as velhas práticas, incabíveis para um mundo em que os recursos tecnológicos estão por todas as partes. É preciso inovar, transformar a educação em um momento prazeroso, que o aluno se sinta participante e sujeito de tudo o que aprender. Só assim é possível avançar no objetivo de criar alunos que sejam cidadãos, que façam a diferença e deixem sua marca no mundo. 
A questão da aprendizagem de língua inglesa, como esse artigo mostrou, é pautada sempre nas tendências do momento. Inicialmente, as línguas estrangeiras serviam para ler e escrever, pois uma pessoa que tinha o conhecimento da literatura em latim ou grego, por exemplo, era tida como culta e parte de uma classe social mais elevada.

Com a necessidade da transformação e o advento da ascensão de novas línguas à posição de poder, como aconteceu com a francesa e a alemã que, mais tarde, foram substituídas pela inglesa, passou-se a focar em vocabulário, como o Método Direto, e em diálogos seguidos de drills, com o Método Áudio-lingual. Essa evolução só demonstrou que cada método tentava dar conta da necessidade linguística da época, o que já não é mais uma verdade no século XXI.

Certamente, não se pode desconsiderar as velhas práticas e hábitos, mas elas precisam ser remodeladas e repensadas para os alunos que estão em sala hoje. São os nativos digitais que ditam o ritmo de sua aprendizagem, pois aprendem melhor por meio de processos ativos, em que se tornam agentes de seu próprio conhecimento. Não obstante, os nativos digitais também têm uma conexão forte com as tecnologias, e elas se apresentam como recursos ostensivos na aprendizagem, não apenas de língua estrangeira, mas de todas as disciplinas curriculares, por meio das multimodalidades e do letramento digital.

Buscando encontrar uma aplicação dos jogos digitais na realidade educacional, este artigo apresentou a relação entre a aprendizagem mediada por jogos digitais, DGBL, e os games na aula de língua inglesa. Traçando uma linha para compreender a relação destes com o letramento digital, os autores destacam que é possível utilizá-los e que, se o foco for a liberdade e autonomia do aluno em detrimento de sua aprendizagem, é possível usá-los como recurso para enriquecer, e não como um substituto do professor.

A partir da análise e da proposta de cinco jogos, a relação dos jogos com a língua e com uma perspectiva interdisciplinar foi observada e apresentada. Ainda que os games aqui descritos não tenham finalidade educacional, mostraram-se como recursos que possibilitam a prática contextualizada da língua, a flexibilização do espaço de aprendizagem, a discussão sobre temas sérios da sociedade e um meio de se abordar conteúdos curriculares em um espaço motivador e divertido. 
Um ponto que pode mostrar-se desfavorável, mas deve ser pensando como investimento para a promoção da língua em contextos como foi tratado no artigo, é a questão do valor dos jogos sugeridos. Todas as opções sugeridas são pagas, mas permitem cópias adicionais e/ou a flexibilização no seu uso. No caso de The Sims 4, por exemplo, o valor pode ser alto, mas permite uma exploração infinita no quesito dos papeis sociais, das diferentes realidades e dos questionamentos morais.

Ressalta-se que os papéis incumbidos ao professor não mudam para essa abordagem, apenas é necessário que ele, como/se imigrante digital, possa ter contato com os video games para preparar suas aulas e criar propostas adequadas para sua aula. O foco dado ao jogo pode promover esse espaço de troca e contexto, que a língua tanto necessita para se desenvolver.

Por fim, ainda que exista este espaço e que teorias, como o letramento digital, tragam a necessidade emergente da presença tecnológica em sala, é importante que os velhos hábitos sejam postos em prova, permitindo que o novo também faça parte dessa realidade. É só por meio de mais pesquisas e práticas que se chega ao uso efetivo das tecnologias.

\section{Referências}

AL-QALLAF, Charlene L.; AL-MUTAIRI, Afaf S.R. Digital literacy and digital content supports learning: The impact of blogs on teaching English as a foreign language. The Electronic Library, Texas, US, v. 34, n. 3, p. 522-547, 2016.

BRAGA, Denise Bértoli; RICARTE, Ivan Luiz Marques. Letramento na era digital: construindo sentidos através da interação com hipertextos. Revista da ANPOLL, IELUNICAMP, Campinas, SP, v. 18, p. 59-82, 2005.

CASTELLS, Manuel. A sociedade em rede: a era da informação: economia, sociedade e cultural. São Paulo: Paz e Terra, 2007.

CITIES: Skylines. Stockholm, SE: Paradox, 2015. 1 jogo eletrônico.

COYLE, Do; HOOD, Philip; MARSH, David. Content and Language Integrated Learning. United Kingdom: Cambridge University Press, 2010.

CRUZ, Fabielle Rocha. Letramento digital em língua inglesa: limites e potencialidades de Sid Meier's Civilization V. In: MACHADO, Gabriella Eldereti, SEVERO, Bianka de Abreu (org.) Linguagens em movimento no ensino: atravessamentos e experiências. São Paulo: Pimenta Cultural, 2020, p. 49-69. 
DON'T Starve Together. Vancouver, CA: Klei Entertainment, 2016. 1 jogo eletrônico.

GEE, James P.; HAYES, Elisabeth R. Language and Learning in the Digital Age. United States: Routledge, 2011.

GEE, James P. Teaching, learning, literacy in our high-risk high-tech world. United States: Teachers College Press, 2017.

HUMMEL, Kirsten M. Introducing Second Language Acquisition: Perspectives and Practices. United Kingdom: Wiley Blackwell, 2014.

LARSEN-FREEMAN, Diane. Techniques and Principles in Language Teaching. New York: Oxford University Press, 2008.

MAGNANI, Luis Henrique. Videogames, letramentos e construção de sentidos. In: TAKAKI, Nara Hiroko; MACIEL, Ruberval Franco. Letramentos em terra de Paulo Freire. Campinas, SP: Pontes Editores, 2015, p. 43-61.

MOHAMMADYARI, Soheila; SINGH, Harminder. Understanding the effect of elearning on individual performance: The role of digital literacy. Computers \& Education, Amsterdam, NL, v. 82, p. 11-25, 2015.

ORWELL. Australia: Fellow Traveller, 2016. 1 jogo eletrônico.

OVERCOOKED 2!. Wakefield, UK: Team 17, 2018. 1 jogo eletrônico.

PRENSKY, Marc. Don't bother me Mom - I'm learning!: How computer and video games are preparing your kids for twenty-first century success - and how you can help!. United States: Paragon House, 2006.

PRENSKY, Marc. Digital Game-Based Learning. United States: Paragon House, 2007.

RYBERG, Thomas. GEORGSEN, Marianne. Enabling Digital Literacy. Nordic Journal of Digital Literacy, Oslo, NO, v. 5, n. 02, p. 88-100, 2010.

SHAFFER, David W. How computer games help children learn. United States: Palgrave Macmillan, 2006.

THE SIMS 4. California, US: Electronic Arts, 2014. 1 jogo eletrônico.

ZACCHI, Vanderley José. Dimensões críticas no uso de jogos digitais. In: TAKAKI, Nara Hiroko; MONTE MÓR, Walkyria. Construções de sentido e letramento digital crítico na área de línguas/linguagens. Campinas, SP: Pontes Editores, 2017, p. 221241. 